\title{
OBJETOS DE LA GUBERNAMENTALIDAD: LA DIMENSIÓN EPISTÉMICA DEL CONSUMO DE DROGAS EN EL ESTADO CHILENO*
}

\author{
Nicolás Sanhueza Rodríguez ${ }^{* *}$
}

\section{RESUMEN}

Este artículo tiene por objetivo evidenciar la emergencia, articulación y alcances de un objeto que caracteriza la dimensión epistémica de la drogadicción, en la esfera pública en Chile. Buscando estudiar los procesos de producción de conocimiento científico de este problema social, desarrollamos un análisis empírico de las prácticas de científicos sociales que trabajan en un centro de estudio público, responsables de la producción de evidencia científica en la materia. Entregamos evidencia de las diferentes dinámicas, orientaciones y objetos que se producen, a la hora de elaborar el conocimiento científico social del consumo de drogas, que contribuyen a su elaboración y delimitación como un problema social desde el Estado. Los resultados nos evidencian el rol preponderante del Estado, en alianza con las ciencias sociales positivistas, a la hora de producir Boundary Objects, capaces de articular un conjunto de actores, practicas, instituciones y conocimientos diversos, en vista de objetivos gubernamentales comunes.

PALABRAS CLAVE: GUBERNAMENTALIDAD - CONOCIMIENTOS CIENTÍFICOS ESTADO - BOUNDARY OBJECT

* Esta investigación contó con el financiamiento del Proyecto de Investigación Fondecyt No 1.121.124 "Datos y relatos científico sociales que dan forma a la realidad social de Chile: Estudio de los entrelazamientos constructivos y performativos de la ciencia social", cuyo investigador responsable es el profesor Dr. Claudio Ramos Zincke (Departamento de Sociología, Universidad Alberto Hurtado, Chile). Agradezco los comentarios y aportes de Sebastián Ureta, Martin Pérez Comisso y Karen Espínola, que fueron realizados a versiones previas a este artículo; he considerado incluir la mayoría en este escrito final.

** Instituto de Sociología, Pontificia Universidad Católica de Chile. Correo electrónico: $<$ nsanhueza@uc.cl>. 


\section{INTRODUCCIÓN}

El Estado, en su articulación más reciente, al igual que otras instituciones, se vale de diversos mecanismos y estrategias que le permitan un control e intervención en la población. Distintos estudios permiten visualizar orientaciones liberales que el Estado moderno ha tenido desde el siglo XviII, que buscan robustecer en este tipo de estrategias y mecanismos de poder (Porter, 1995 y 2003; Wagner, 2003; Desrosières, 2004; Carroll, 2006; Foucault, 2007; Ramos, 2012 y 2016).

Pero, además, por su desarrollo y complejidad, el Estado ha incorporado un conjunto de procesos performativos (Ramos, 2012), que dan forma a la realidad exterior (Bourdieu, 2012). Es decir, el Estado no solo describe realidad e interviene a través de políticas públicas y programas sociales, sino que también participa en la construcción de esta (Ramos, 2012 y 2016). Particularmente, el Estado desarrolla esta función performativa fortaleciendo el vínculo con las ciencias sociales, a través de una serie de mecanismos y recursos invertidos (humanos, tecnológicos, metodológicos, presupuestarios, entre otros). Esto ha posibilitado perfeccionar la capacidad gubernamental que el Estado tiene no solo de capturar determinados conocimientos y fenómenos sociales, sino que además juega un rol preponderante en la construcción de la realidad o fenómeno mismo. Resulta particularmente necesario entonces poder conocer y describir empíricamente aquellos espacios y objetos institucionales desde donde el Estado produce día a día conocimientos, no solo debido a su importancia desde un punto de vista causal y tradicional, esto es, a mayor evidencia, mayor certeza, sino cómo y cuales son las formas en que el Estado produce conocimiento social específicamente.

En este artículo tratamos de entregar luz a estas interrogante, reflexionando acerca de los diferentes procesos que integran la producción de conocimientos desde el Estado chileno y en particular con un caso de estudio: El Observatorio Chileno de Drogas. Para eso, a través de diferentes observaciones empíricas, buscamos entregar una reflexión sobre las prácticas, formas y estrategias cotidianas que se dan en esta institución responsable de producir conocimientos.

\section{LA DROGADICCIÓN COMO UN PROBLEMA EPISTÉMICO}

Hace treinta años poco se sabía y hablaba de las drogas y el alcohol en nuestro país. Era poco común que en las conversaciones familiares se hablara 
de que en otros países se utiliza la marihuana para el tratamiento del cáncer, o que en los medios de comunicación se presentara un artículo sobre el aumento en los índices de consumo de drogas en población escolar. Poco y nada se sabía del Cannabis Abuse Screening Test, o del Alcohol Use Disorders Identification Test. En los últimos años vemos cómo estos, y otros temas vinculados a las drogas y el alcohol se vuelven parte de nuestra cotidianidad, de las conversaciones con amigos o colegas del trabajo, quizás luego de una consulta médica o de haber leído una noticia. Ya sea la drogradicción en general, o el consumo de drogas y alcohol en particular, estos fenómenos pueblan las relaciones sociales e interpersonales. Ahora bien, ¿por qué la drogadicción emerge en el último tiempo como un fenómeno preponderante en nuestra sociedad? ¿Quiénes son los que articulan este tipo de fenómenos? ¿Quiénes elaboran los conocimientos que dan forma a la concepción pública de la drogadicción en Chile? ¿Qué rol cumple el Estado en la concepción y delimitación de lo que hoy se entiende por consumo de drogas?

El fenómeno de la drogadicción, o el consumo nocivo de sustancias ilícitas se ha venido estudiando sistemáticamente, ya sea en Chile como en el continente latinoamericano, por diferentes disciplinas, expertos, y organizaciones especializadas, en los últimos treinta años (Florenzano, 1989; Hopenhayn, 1997; Hopenhayn, Rementería y Sunkel, 1999; Arriagada y Hopenhayn, 2000; Peruaga, Rincón y Selin, 2002; Rebolledo y Costa, 2005; Garmendia, Alvarado, Montenegro y Pino, 2008; Valenzuela y Larroulet, 2010; Sánchez, 2012; Fernández, 2013). Su estudio, al igual que otros fenómenos sociales como la pobreza, la violencia doméstica o la delincuencia, demanda un conjunto de dispositivos epistémicos, lo que permite delimitarlos y definirlos (Ramos, 2016). Kreimer y Zabala (2007) señalan precisamente que en Latinoamérica la producción de conocimiento científico ha sido reconocida "como una estrategia de intervención legítima sobre los problemas sociales [...] a los que se encuentra sometida la población de América Latina" (Kreimer y Zabala, 2007: 111).

Para poder entender de manera cabal cómo operan la producción de conocimientos vinculada a este tipo de problemas sociales, es necesario profundizar en la comprensión de la relación entre Ciencia y Estado. Uno de los autores que más evidencia y antecedentes ha entregado en esta materia ha sido Michel Foucault (Foucault, 2002; 2005; 2006 y 2009), quien a partir del concepto de gubernamentalidad ha evidenciado un conjunto de procesos que se han venido desencadenando en los Estados Modernos desde mediado del siglo xx. 
Desde su constitución, las sociedades modernas en el transcurso del siglo XVII al XVIII -argumenta Foucault- presentan una expansión de las tecnologías disciplinarias, lo que deriva en una evolución en la tecnología de poder, que en términos generales se expresa en el cambio de un poder soberano (basado en el manejo de territorio, productos y sus habitantes), en un dispositivo de poder más eficiente llamado poder disciplinar ${ }^{[1]}$ (que se orienta al ejercicio individual, buscando el control y la normalización de la conducta humana). Como sabemos, para Foucault el ejercicio del poder necesita de aparatos del saber, que permiten delimitar sus ámbitos de la dominación (Foucault, 2000), pero con la emergencia del conocimiento científico en el siglo XVIII, esta relación entre poder y saber se complejiza (Ramos, 2012). El poder disciplinario se despliega a través de diferentes mecanismos los cuales buscan generalizar saberes en regímenes de verdad (o cuerpos de conocimiento científico) (Ramos, 2012: 118).

Bajo estos antecedentes, la gubernamentalidad sería el proceso histórico que viene a contextualizar la emergencia de este nuevo dispositivo de poder, el cual opera sobre los seres humanos, buscando politizar su vida (Ramos, 2012). La gubernamentalidad es una tecnología de poder más abarcativa, que incluye nuevas tecnologías de poder, buscando la gestión de conductas, su emergencia -sostiene Foucault- está directamente vinculada a los conocimientos científicos de las ciencias sociales (Foucault, 2007). Ramos (2012) precisa que la gubernamentalidad -para Foucault- posee cinco focos de atención clave. Primero, las prácticas administrativas estatales de control sobre los ciudadanos; segundo, las estadísticas; tercero, los saberes de las ciencias sociales; cuarto, los sistemas de información y manejo de datos, y, por último, los procesos poblacionales; en otras palabras: "Se trata [...] de la complejización de los fenómenos o procesos poblacionales [...], asociada al crecimiento de su tamaño y a la expansión de la actividad económica y de la vida urbana” (Ramos, 2012: 77).

Tal como lo sostiene Ramos (2016), lo que ha caracterizado la constitución del Estado moderno ha sido su dimensión epistémica y donde las ciencias sociales han jugado un rol preponderante (Ramos, 2016: 71). Particularmente, señala Ramos (2016), existen fenómenos sociales que pueblan nuestra sociedades actuales, tales como la delincuencia, la violencia, la pobreza o la drogadicción, sobre los cuales la gubernamentalidad opera. De

[1] Ramos (2012) seńala que los mecanismos disciplinarios "sirven de base para la generación de saberes que, inicialmente asociados a la labor del disciplinamiento van constituyendo sus propios regímenes de verdad, como cuerpos científicos de conocimiento" (Ramos, 2012: 118). 
esta manera, el estudio de estos "problemas sociales" nos provee de una mejor comprensión de esta dimensión epistémica del Estado.

Este estudio se enmarca bajo el Proyecto de Investigación Fondecyt No 1.121.124: "Datos y relatos científicos sociales que dan forma a la realidad social en Chile" y cuyo investigador responsable fue el profesor Claudio Ramos. Dicho proyecto consideró estudiar dos grandes formas de construcción de la sociedad. La vía que sigue este artículo es la de los datos, la cual tiene un cohorte positivista (a partir de datos estadísticos, indicadores y variables), los cuales tienen una fuerte presencia en la esfera de la gestión estatal (Ramos, 2016). ${ }^{[2]}$

En esta línea, este artículo tiene por objetivo evidenciar el estudio empírico de los procesos de producción de conocimientos de problemas sociales, que operan como dispositivos de poder gubernamental. Así, a través de la realización de un estudio de casos, buscamos obtener mayores antecedentes sobre la interacción de actores, objetos, mecanismos y alcances de la producción de conocimientos científicos de este tipo de fenómenos por parte del Estado y su dimensión epistémica. Buscamos conocer y describir empíricamente, qué practicas cotidianas constituyen y se despliegan en una organización pública encargada de producir evidencias y datos científicos sobre la drogadicción en Chile.

\section{LA DROGADICCIÓN COMO UN PROBLEMA SOCIAL}

En Chile, la política pública vinculada a la prevención del consumo de drogas y alcohol ha estado marcada por el desarrollo dos ámbitos: uno normativo, ${ }^{[3]}$ y por otro lado lo referido al diseño e implementación de organizaciones tales como el Consejo Nacional para el Control de Estupefacientes y en la actualidad el Servicio Nacional para la Prevención y Rehabilitación del Consumo de Drogas (SENDA), los cuales han elaborado una serie de herramientas y dispositivo de gestión y administración para la medición e intervención del fenómeno de la drogadicción en Chile, tales como la

[2] La segunda línea de estudio de este proyecto, el cual no se revisa en este artículo, ha sido la performatividad de los relatos sociológicos (de sus narrativas y construcciones argumentativas). Para mayor información, consultar Ramos (2012, 2013, 2014, 2015 y 2016).

[3] A través de las modificaciones al Código Penal (1873 y 1969), así como también en la promulgación de leyes de drogas y alcoholes (Ley No 17.934 de 1973, Ley No 18.403 de 1985, Ley No 19.366 y Ley No 19.419 de 1995, Ley No 19.925 de 2004 y Ley No 20.000 del 2005). 
Política y Plan Nacional de Prevención y Control de Drogas del año 1992, la Estrategia Nacional sobre Drogas 2003-2008, la Estrategia Nacional sobre Drogas 2009-2018, la Estrategia Nacional de Drogas 2011-2014, y los Programas "Chile Previene" y "Chile Recupera"; así como el Sistema de Registro y Procesamiento de la Información, o la Encuesta Nacional de Drogas 1994, la cual se sigue implementando hasta la actualidad.

En el año 1990, se crea en Chile el Consejo Nacional para el Control de Estupefacientes (CONACE), institución estatal encargada de la elaboración de políticas públicas en esta materia lo cual inaugura un nuevo proceso desde el Estado con respecto al funcionamiento y entendimiento del consumo de drogas en la sociedad chilena. A finales del siglo xx, estas transformaciones estatales se ven alteradas significativamente a partir de la implementación del Programa Bienal de Estudios Nacionales sobre Drogas y sus Factores Asociados en la Población General de Chile, que el Estado, a través del CONACE, decide implementar desde el año 1994 a la actualidad. A la fecha se han realizado 11 estudios (conocidos como Estudios Nacionales de Población General).

Esta serie de estudios empíricos fueron mediciones cuantitativas de tipo descriptivo, los cuales buscan "caracterizar cuantitativamente a la población seleccionada", y con ello poder determinar el consumo o prevalencia de drogas en la vida de los individuos (CONACE, 1994: 32). Dichos estudios fueron diseñados en los primeros ańos por diversos equipos profesionales, los cuales eran coordinados por la Secretaría Ejecutiva del CONACE. Aquí participaron diversos profesionales provenientes de ministerios y servicios del Estado (como el Instituto Nacional de Estadística, que contribuye a la selección de la muestra a partir de los datos recopilados en el Programa Integrado de Encuesta de Hogares - PIDEH- e información del Censo Nacional, según el año correspondiente), e instituciones universitarias (tales como el Instituto de Salud Pública de la Universidad de Chile y el Centro de Información Toxicológica de la Universidad Católica de Chile), entre otras.

La puesta en marcha de un programa de estudios de esta envergadura derivó en la producción de una gran cantidad de datos que han sido recopilados y sintetizados en bases de datos electrónicas desde el año 1994. Claro está, al producirse esta inmensidad de información y datos sobre el consumo poblacional de drogas en Chile, se debía tener un objetivo, un determinado lineamiento gubernamental o una función en la acción estatal. Pero esta idea en los comienzos del CONACE no fue evidente. En la primera etapa, este conjunto de datos y mediciones del fenómeno de la droga debía consolidar un Sistema Nacional de Información de Drogas, algo así 
como un sistema informático con datos objetivos y actualizados del fenómeno de la droga en Chile. ${ }^{[4]}$

Transcurridos varios años de funcionamiento del CONACE, el Estado buscará orientar esta carencia de gestión y análisis de la información producida en el contexto del Programa de Estudios Nacionales de Drogas. Surge así la idea de contar con un Área de Evaluación y Estudios en el año 2008. Esta permitiría coordinar la implementación de los Estudios Nacionales y además llevar a cabo labores formales y concretas de análisis y gestión de información recopilada, procesada y alojada en bases de datos electrónicas. Con todo, la implementación de estos estudios es aprobada año tras año, y el aumento de producción de datos estadísticos se suma a la formulación de proyectos emblemáticos en el interior del servicio, tales como "Chile Previene" y "Chile Recupera". En este período se comienza a gestar la idea de transformar al CONACE en un órgano independiente al trabajo interministerial, con ciertos grados de autonomía. La propuesta de reformulación del CONACE a un Servicio Nacional vino -entre otras- fundamentada desde el interior del Estado, a través de un conocido informe de la Dirección de Presupuesto (DIPREs) del Ministerio de Hacienda (2009), el cual hacía referencia a la cantidad de presupuesto asignado y el personal contratado a la fecha, lo cual no tenía relación con un Consejo Asesor, sino más bien con la figura organizacional de un Servicio Nacional.

En el año 2011 se crea el nuevo Servicio Nacional para la Prevención y Rehabilitación del Consumo de Drogas y Alcohol (sENDA), el cual reemplaza al CONACE como la oficina estatal responsable de la ejecución de políticas públicas en materia de prevención y tratamiento del consumo de drogas y alcohol. En este nuevo contexto de transformación institucional -y según lo estipulado en la Ley No 20.502- es necesario elaborar un documento que sirva para orientar la puesta en marcha del nuevo servicio. Dicho documento será la Estrategia Nacional de Drogas y Alcohol (2011-2014). En dicha publicación se establecen los lineamientos estratégicos del nuevo servicio, especialmente a los programas "Chile Previene" y "Chile Recupera", pero profundizando en la idea de reformulación del área de Evaluación y Estudios, a través de la implementación de una organización especializada que sea capaz de: "ofrecer un diagnóstico permanente del mercado de la droga en Chile, sirviendo de insumo para la propuesta y evaluación de las políticas de control" (CONACE, 2011: 18). A dicha organización se la denomina Observatorio Chileno de Drogas y Alcohol.

[4] Más información en CONACE (1994).

REDES, VOL, 26, № 50, BERNAL, JUNIO DE 2020, PP, 71-104 


\section{PRODUCCIÓN DE CONOCIMIENTOS CIENTÍFICOS}

Nuestro estudio propone abordar el problema de la producción de conocimientos en el Estado, a partir de un conjunto de enfoques teóricos recientes con fuerte vocación empírica. Primero, rescatando las propuestas etnometodológicas de los estudios de etnografías de laboratorio (Latour y Woolgar, 1979), y a su vez rescatando la aproximación semiótico-material de la teoría del actor-red (Star y Greiseimer, 1986; Callon, 1995; Law, 2004). Estos enfoques han surgido en el seno de los Estudios en Ciencia, Tecnología y Sociedad (ст)), buscando: "describir y entender las claves epistemológicas y ontológicas que hacen posible (o imposibilitan) la emergencia de constructos científicos y técnicos" (Ureta y Sanhueza, 2018: 21). Con ello, buscamos poner en diálogo dos perspectivas convergentes, por un lado, los estudios CTS y por otro, los ya mencionados estudios de la gubernamentalidad de Foucault y de la performatividad de Ramos (2012 y 2016).

Ramos (2012) menciona que la gubernamentalidad funciona a partir de mecanismos performativos, haciendo referencia a procesos que describen y a su vez construyen la realidad (Ramos, 2016: 29). Este doble proceso de involucramiento y construcción del mundo, ${ }^{[5]}$ que se articula en los aparatos estatales, específicamente en la producción de conocimientos científico-sociales, tiene directa relación con cómo los estudios CTs han investigado la construcción de hechos científicos, a partir de prácticas que construyen la ciencia (Latour y Woolgar, 1979). Ramos (2012) propone ciertas condiciones de operación para la performatividad en ciencias sociales, en especial la legitimidad social del conocimiento científico y sus mecanismos operativos para la performación, los cuales están compuestos por:

1. Redes de individuos. Una red es una "trama de relaciones, toda una malla por la que circula el conocimiento, experimentando transformaciones que lo hacen asimilable y empleable por parte de diferentes integrantes de agencias no científicas -por ejemplo, entidades estatales o corporativos de negocios- que se entrelazan con esta malla o que entran en contacto con ella" (Ramos, 2012: 147).

2. El equipamiento e instrumentos. Entendidos como: "[...] desde simples hojas de papel hasta capturadores de datos y complejos programas incorporados en computadores de alta capacidad" (Ramos, 2012: 147).

[5] Ramos (2016) señala que esta noción ha sido elaborada a partir del trabajo clásico de Berger y Luckmann (1967), el cual influyó a los estudios cts y a la sociología en general. 
3. Las organizaciones. Las cuales tienen directa relación con el uso del conocimiento científico y la performación de conductas o comportamientos, sobre todo en el ámbito de la gestión pública (Ramos, 2012: 148).

4. Los textos y publicaciones. Los cuales, "revestidos de confianza y legitimidad otorgados por la ciencia, hacen circular, en múltiples traducciones y reempaquetamientos, el contenido proposicional científico" (Ramos, 2012: 150).

A su vez, una aproximación empírica al estudio de los procesos de producción, elaboración, justificación y difusión de conocimientos científicos ha sido la tradición inaugurada por los conocidos Estudios o Etnografías de Laboratorio (Latour y Woolgar, 1979; Knorr-Cetina, 1981; Lynch, 1985; Traweek, 1988), que, con herramientas de la sociología del conocimiento y la etnometodología, ingresaron a estudiar empíricamente diversos laboratorios en los Estados Unidos. Estas investigaciones empíricas "buscaron describir y analizar la ciencia, no a través de los discursos de los científicos o la reconstrucción histórica de casos, como se había hecho hasta ese momento, sino a través de la descripción detallada de las prácticas cotidianas por medio de las que se producía la ciencia, las cuales hasta la fecha habían sido escasamente investigadas" (Ureta y Sanhueza, 2018: 37).

Los Estudios de Laboratorio se preguntan por los procesos mismos de formación de una teoría, buscando demostrar que había toda una política dentro de los laboratorios (incluso más que afuera de ellos). Así, el estudio de la producción de hechos científicos deja de ser el punto de partida, pasa a ser el de llegada (Ureta y Sanhueza, 2018). Para este conjunto de investigaciones hay un carácter fuertemente idiosincrático y cotidiano en los procedimientos de producción de conocimientos. Tal como señalan Ureta y Sanhueza (2018), los Estudios de Laboratorio radicalizan "el movimiento, ya iniciado por Kuhn, de desacralizar la ciencia, mostrándola como un tipo de trabajo, si bien altamente sofisticado, no exento de las particularidades y limitaciones de cualquier actividad humana" (Ureta y Sanhueza, 2018: 38).

Buscando entregar nuevos antecedentes a este campo de estudios, Star y Greiseimer (1989) describen los diversos mecanismos de coordinación y gestión de la información que se requieren por parte de distintos actores involucrados en el trabajo de elaboración de una guía de flora y fauna en un museo de California. Ellos señalan que el trabajo científico demanda, por un lado, comprender la coordinación entre mundos en la actividad científica, y a la vez, profundizar en la necesidad de generalizar resultados 
para obtener hallazgos. El trabajo científico está conducido por un extrema diversidad de actores, intereses y procesos en vías de estandarización.

Así, es común observar diversos equipos de investigadores, disciplinas y de distintos mundos epistémicos que confluyen. Es así como el trabajo científico en nuestra sociedad se ha transformado en una empresa compuesta por actores y puntos de vista heterogéneos (Star y Greiseimer, 1989: 388). Los autores precisan que:

La creación del conocimiento científico depende de la comunicación, así como también de la creación de nuevos hallazgos [...]. Pero debido a estos nuevos objetos y métodos, que significan diferentes cosas según los mundos, los actores están enfrentados a la tarea de conciliar estos significados, si es que ellos desean cooperar [...]. Esta "reconciliación" requiere de una labor sustancial de todos los que forman parte [del proceso]. Los científicos y otros actores contribuyen a la traducción científica, a la negociación, al debate, a la triangulación y a la simplificación en pos del trabajo en conjunto (Star y Greiseimer, 1989: 388-389).

En esta misma línea, Callon (1995) sostiene que los procesos de interesamiento y traducción son fundamentales para entender la producción de conocimientos. Callon (1995) destaca la necesidad del logro de acuerdos y la reconciliación de diversos puntos de vista entre los actores. Para él, cosustanciales a estos procesos de coordinación de las acciones individuales en acciones colectivas son los procesos de sometimiento de algunos actores sobre otros, a través del interesamiento y la traducción, que les permiten invocar una autoridad científica para someter la acción del resto de los actores involucrados (Star y Greiseimer, 1989: 389). De esta manera, los participantes son "alistados" para reinterpretar sus propias preocupaciones y asimilarlas a los objetivos programáticos de los que han invocado esta autoridad. Estos actores serán establecidos como "porteros" (Callon, 1995: 265) y serán los encargados de implementar un "punto de paso obligado" en el proceso de traducción. Esta acción ocurre de tal manera que permita aumentar la centralidad del trabajo del actor que realiza este proceso, el cual se ha conceptualizado como interesamiento (Callon, 1995), es decir, aquel proceso que indica la acción de traducir preocupaciones no-científicas en aquellas científicas, para así orientar la acción de uno o varios actores (Star y Greiseimer, 1989).

Sin embargo, Star y Greiseimer (1989) precisan que: "la naturaleza final del interesamiento, no puede ser entendida desde un solo punto de vista" (Star y Greiseimer, 1989: 389), es decir, pueden existir múltiples traduc- 
ciones, así como también "puntos de paso obligatorio" en este proceso. ${ }^{[6]}$ A diferencia de la aproximación de Callon (1995), donde parece haber más bien una canalización a la hora de presentar la mediación de varios intereses, es decir, solo una traducción hegemónica, disciplinar y epistemológicamente. Contrariamente, para Star y Greiseimer (1989), "la unidad es la empresa entera", lo cual implica una "mecánica de las asociaciones y el modo como ellas soportan la tensión entre cooperación y heterogeneidad" (Trompette y Vinck, 2010: 5). Así, los procesos de interesamiento están vinculados a una determinada coherencia (individual y organizacional) de todas las traducciones que están siendo parte de este proceso, las cuales dependen de los esfuerzos que los actores involucrados, independientemente de los mundos sociales de que provengan (Star y Griesemer, 1989: 390). Es así como los procesos de traducción, en la producción de conocimientos, se vuelven indeterminables y contingentes. Sin embargo, aún es necesario pesquisar cómo se logra "reducir la incertidumbre a nivel local, sin correr el riesgo de la pérdida de cooperación entre aliados" (Star y Greiseimer, 1989: 391).

Para esto, Star y Greiseimer (1989) proponen utilizar la noción interpretativa de Boundary Object, ${ }^{[7]}$ la cual invita "a pensar en la acción colectiva y la innovación desde una perspectiva ecológica, poniendo en escena los artefactos diversos que intervienen en la articulación de conocimientos distribuidos" (Trompette y Vinck, 2010: 10).

Los Boundary Object son:

[...] objetos que son, a la vez, lo suficientemente plásticos para adaptarse a las necesidades locales y a las limitaciones de varios actores que los emplean, pero lo suficientemente robustos para mantener una identidad a través de los sitios (Star y Greiseimer, 1989: 393).

[6] Para poder desarrollar esta idea, Star y Greiseimer (1989) rescatan el enfoque ecológico-institucional desarrollado por Everett Hughes (1897-1983). El análisis ecológicoinstitucional (Star y Ruhleder, 1996) permite analizar las diferentes posturas epistemológicas entre los actores involucrados en estos procesos, así como también sus puntos de vista. En dicho análisis, Hughes se refiere a la importancia del medio ambiente de las instituciones, donde cada institución "elige" su medio ambiente (esta es parte de sus funciones orgánicas). De esta manera es como las organizaciones actúan internamente para poder definir sus límites, su entorno y de acuerdo con estas definiciones cómo definir sus recursos, sus clientes, su personal (grados y tipos), entre otras (Star y Greiseimer, 1989: 389).

[7] El concepto Boundary Object ha tenido diferentes traducciones e interpretaciones (objetos de frontera, objeto límite, etc.). Hemos decido dejarlo en su idioma para no perder su riqueza conceptual. Más información se puede encontrar en Trompette y Vinck (2009). 
Esta noción nos permite analizar la interacción de actores (humanos y no humanos) que provienen de mundos sociales diversos y que han logrado coincidir en intereses particulares, para el logro de tareas y demandas científicas relacionadas con el análisis y gestión de la información y conocimientos.

Estos objetos emergen en espacio de trabajo donde es necesario procesar y gestionar grandes cantidades de información, gozan con una gran capacidad de adaptación a necesidades locales, y desarrollan una fortaleza interna para mantener su identidad en diferentes contextos (Star y Greiseimer, 1989: 393). Es así como los científicos deciden poner sus esfuerzos y cooperación en la construcción de estos objetos del conocimiento, que emergen como resultado de procesos de elaboración y gestión de la información, a través de determinados grados de cooperación entre ellos.

Estos objetos ${ }^{[8]}$ están estructurados para el uso común, pero a la vez, se vuelven fuertemente estructurados y específicos en los espacios de uso individual (Star y Greiseimer, 1989: 393). Su emergencia está condicionada al trabajo diversos actores para producir representaciones de una naturaleza o fenómenos que están tratando de ser definidos y consensuados (Star y Greiseimer, 1989: 408).

\section{METODOLOGÍA}

Esta investigación adopta un acercamiento paradigmático interpretativo (Denzin y Lincoln, 2008 y 1998; Geertz, 1992; Guba y Lincoln, 1998 y 2002; Taylor y Bogdan, 2000; Wolcot, 2006; Becker, 2010). Cuando hablamos de un paradigma científico entendemos que es:

una matriz cognoscitiva disciplinaria [...] [que] busca mostrar que el proceso de producción de conocimiento científico no ocurre asépticamente en un vacío sociocultural, sino que está cruzado y marcado por creencias y valores derivados del marco sociocultural en que ocurre tal producción de conocimientos, así como por procesos psicosociales de las comunidades de investigadores (Ramos, 2005: 86-87).

[8] La noción se vincula a la de un intermediario que "hace vínculo" constantemente entre entornos, discursos y actores; pero además "es vehículo", ya que tiene la capacidad de transportar información y modelos de conocimiento (análisis, interpretación, discusión, etc.), posibilitando la coordinación -en diferentes espacios y contextos- de la actividad científica. El análisis conduce a los autores a identificar cuatro tipos de objeto frontera (el repertorio, el ideal tipo, la envoltura, el formato estándar). 
Dentro de este paradigma, existen diversas técnicas o herramientas metodológicas, tales como la etnografía, observaciones participantes, entrevistas, etc. Para este enfoque, la realidad es una construcción individual que se coconstruye entre el sujeto y el medio. Denzin y Lincoln (2008) entienden que esta es una actividad que localiza al observador en el mundo, que consta de un set de prácticas interpretativas materiales que hacen al mundo visible y que deben ser sistematizadas bajo anotaciones de terreno, entrevistas, conversaciones, fotos, grabaciones, etc. Hammersley y Atkinson (2001) señalan a su vez que

en una cultura gráfica es posible apoyarse en todo tipo de relatos escritos desde "dentro", documentos producidos especialmente para los propósitos de la investigación y los generados para otros propósitos (Hammersley y Atkinson, 2001: 176).

Así, los investigadores sociales no debieran tomar por "secundarios" los documentos oficiales que pudiera presentar el contexto que se está analizando. De hecho, el etnógrafo que se interna en el complejo sistema burocrático de la administración pública debiera seguir un examen detallado de los lugares donde la producción y el uso de los documentos son un mecanismo integral de los distintos elementos (materiales o inmateriales) del quehacer cotidiano. Estos datos o información oficial no debieran ser desperdiciados, de hecho: "[...] en vez de verlos como fuentes de información (más o menos sesgada), los documentos y estadística oficiales deberían tratarse como productos sociales; deben ser analizados, y no empleados como recursos" (Hammersley y Atkinson, 2001: 177).

En esta investigación se aplicó un enfoque metodológico centrado en las practicas de los sujetos que componen esta organización. Lo que nos permita describir y explicar cuáles son sus actos, sus practicas, sus rutinas, los procedimientos, los objetos y las formas en que ellos mismo describen su rol como investigadores. Así, buscamos estudiar las relaciones que tienen los actores con los objetos que producen, y cómo estos han llegado a definir y coproducir en un entramado relacional (Marrero, 2013). Estudiar la producción de conocimientos que se genera en este tipo de organizaciones, desde un punto de vista sociotécnico (Latour, 2005), entonces, significa entender lo social como relacional. Seguir objetos en diversos contextos, no significa en ningún caso reducir lo social a lo material, sino permitirnos pensar lo social como algo que está más allá de los objetos. Estudiar objetos nos permite encontrar flujos de redes de agencias (humanas o no humanas) que pueden asociarse a instituciones y organizaciones en la sociedad. 
En este caso, nuestras investigaciones contemplaron un trabajo de observaciones participantes (Goffman, 1989) progresivo en el interior de este centro de análisis y estudios, lo que luego nos llevó a aplicar un conjunto de entrevistas en profundidad ${ }^{[9]}$ a cada uno de los investigadores que componen esta organización.

En el año 2012 accedimos presencialmente a las oficinas del Observatorio Chileno de Drogas, organización dependiente del Servicio Nacional para la Prevención y Rehabilitación del Consumo de Drogas y Alcohol en Chile, lo que nos permitió observar empíricamente una serie de prácticas cotidianas de esta organización. El equipo del Observatorio en este tiempo estaba compuesto por un antropólogo, dos economistas, una socióloga y un psicólogo. Así, el plan de investigación consistió primero en la toma de contacto con la directora nacional del SENDA, con la cual se consensuaron jornadas de trabajo y entrevistas a los miembros del Observatorio Chileno de Drogas del SENDA. Esto derivó en un conjunto de observaciones participantes durante jornadas y reuniones de trabajo, así como en la realización de un conjunto de entrevistas en profundidad ${ }^{[10]}$ a cada uno de los miembros, sumado a otros informantes claves en la organización.

\section{RESULTADOS}

En este artículo intentamos extender la comprensión de la noción de producción de conocimientos sociales en el interior del Estado, como un dispositivo performativo de la gubernamentalidad (Foucault, 2000), que permite dar cuenta de la forma en que se produce y construye la drogadicción como un problema social (Ramos, 2016). Para eso, hemos conducido una investigación empírica en el Observatorio Chileno de Drogas del senda, orga-

[9] Según Taylor y Bogdan (2000), las entrevistas están dirigidas hacia la comprensión de las perspectivas que tienen los agentes estudiados respecto a sus vidas, experiencias o situaciones, expresadas con sus propias palabras, buscándose no contrastar una teoría o supuestos como explicación de un problema, sino más bien, profundizar en ideas más o menos fundadas y hallar explicaciones convincentes o simplemente conocer cómo las personas viven y sienten en situaciones que se relacionan con el problema a investigar (Taylor y Bogdan, 2000: 101).

[10] La entrevista estuvo compuesta por cinco focos de interés: 1) la trayectoria profesional de cada investigador; 2) el trabajo en el observatorio y su estructura organizacional; 3) los mecanismos de producción de datos y evidencias; 4) los canales y mecanismos de difusión, y 5) la comunidad científica disciplinar que se vincula con el trabajo del Observatorio. 
nismo estatal encargado de llevar a cabo las políticas públicas, programas y planes para la prevención del consumo de droga y alcohol en Chile.

Los resultados son consistentes con la tesis de Ramos (2012 y 2016) sobre la dimensión epistémica del Estado y el rol performativo que desempeñan las ciencias sociales en la elaboración y delimitación de problemas sociales, específicamente a través de la producción de datos estadísticos. Esto se confirma a partir de la emergencia de diferentes mecanismos de producción y difusión del conocimiento por parte del Observatorio Chileno de Drogas del SENDA, los cuales se orientan particularmente en la elaboración de una publicación llamada Boletín de Drogas del SENDA. Esta se caracteriza por lo que se describe en los siguientes apartados.

\section{Una publicación individual, con un formato flexible}

Inicialmente, es necesario que cada investigador proponga constantemente relaciones entre variables alojadas en las bases de datos y asociaciones estadísticas. Aquí, el componente de convivencia cotidiana se hace presente en esta etapa de diseño, lo cual es fundamental para el trabajo en equipo, así como también la circulación del diálogo entre todos los investigadores y las jefaturas directas. El trabajo individual de cada investigador se orienta así a la elaboración de este nuevo objeto, que se construye siempre bajo la asociación de las partes como una unidad, es decir, si bien cada investigador realiza un boletín de manera individual, en un comienzo este trabajo traspasa esas fronteras, para ser promovido como el resultado de un trabajo grupal.

Como parte de estos procesos de elaboración, es común observar una flexibilidad a la hora de establecer formatos y estructuras de estos boletines. Así, en los cinco primeros boletines existió un formato estándar, que consideraba: introducción, metodología, resultados y conclusiones, y en algunos casos se agregan: descripción de la muestra, análisis descriptivo, confiabilidad del instrumento, discusión, anexos y referencias bibliográficas. En la mayoría se destaca la referencia a los Estudios Nacionales de Población General, así como también la presencia de análisis estadísticos inferenciales en su mayoría.

Los investigadores deben publicar un boletín mensual, es decir, cada investigador debe elaborar como mínimo dos boletines al año. Esto significa determinar un conjunto de variables a analizar, abrir los archivos electrónicos que contienen las bases de datos de los Estudios Nacionales (realizados en años anteriores), establecer algunas hipótesis que permitan orientar el análisis de los datos, introducir las coordenadas en los programas 
computacionales que permitan determinar la asociación o no entre las variables seleccionadas y luego analizar la presencia o ausencia de asociación estadística. Posteriormente, estos procedimientos deben ser llevados a un documento escrito, de preferencia utilizando gráficos y fórmulas matemáticas que permitan explicar a cabalidad el procedimiento realizado.

\section{Una publicación oficial, que forma parte de metas institucionales}

El boletín también es parte de un conjunto de metas y objetivos institucionales que se deben cumplir por año. La realización de estos boletines fueron incluidos en el Programa para el Mejoramiento a la Gestión (PMG) del SENDA, el cual tiene por objetivo "el cumplimiento de objetivos de gestión a un incentivo de carácter monetario para los funcionarios" ${ }^{[11]}$ Este programa está coordinado por la Dirección de Presupuesto del Ministerio de Hacienda, y permite que cada funcionario reciba una bonificación monetaria a partir del cumplimiento de dichas metas establecidas anualmente.

\section{Una publicación estructurada jerárquica y epistémicamente}

El boletín debe ser elaborado a través del manejo de conocimientos específicos en estadística descriptiva e inferencial (probabilística), utilizando programas computacionales para el análisis de datos, como Excel, sPss o Stata. En este contexto, dos actores se vuelven relevantes a la hora de orientar estas prácticas investigativas del equipo: la directora nacional (socióloga, doctora en Salud Pública), así como la jefa de la División de Tratamiento, la cual es médica y doctora en Epidemiología. Ambas tienen cargos de jefaturas y han sido elegidas por la autoridad política del gobierno. Sumado a ellas, el antropólogo, jefe del Observatorio (estudiante del Doctorado en Salud Pública) y el economista (magíster en Políticas Públicas) juegan un rol fundamental en todo el proceso de elaboración y publicación de los boletines. Todos ellos,

[11] Desde 2014, los PMg cubrirán un total de 194 instituciones y más de 87 mil funcionarios, formando parte de uno de los mecanismos de incentivo de remuneraciones de tipo institucional más importantes aplicados en la administración pública de nuestro país. A partir de 2012, el incentivo monetario corresponde a 7,6\% de las remuneraciones si la institución alcanzó un grado de cumplimiento igual o superior al 90\% de los objetivos anuales comprometidos, y de un 3,8\% si dicho cumplimiento fuera igual o superior a $75 \%$ e inferior a $90 \%$. Véase <www.dipres.gob.cl>. 
desde sus diferentes roles y funciones, destacan por ser actores que tienen mayores conocimientos en la materia y tiempo en la organización. Tanto el antropólogo como el economista son los que publican primero boletines.

Esta presentación de los datos proviene de la epidemiología, área preferencial en la Escuela de Salud Pública en la Universidad de Chile. Y es que para ellos los resultados se trabajan de otra manera [que en Ciencias Sociales], se trabajan en términos epidemiológicos, aquí, para poder decir que una persona está enferma, tiene que ser bajo un modelo teórico perfecto, digamos un experimento controlado. (Fragmento de una entrevista al psicólogo del Observatorio SENDA.)

Una vez iniciado el proceso de elaboración individual de estos boletines se comienzan a presentar borradores a las jefaturas, para su corrección y aprobación; a estos actores los llamaremos "punto de paso obligado", siguiendo la conceptualización que realiza Callon (1995: 265). Los actores que juegan este rol son primero el antropólogo, el jefe del Observatorio, luego la jefa de la División y, por último, la directora nacional. Estos comienzan a realizar correcciones, observaciones y modificaciones a los escritos presentados.

Es importante recalcar el carácter individualizado de este proceso ya que -a diferencia de la primera etapa- el equipo ha tenido que reorientar su trabajo de una manera grupal a una individual, lo cual permite personalizar las revisiones. Aquí, la información se transfiere internamente entre estos actores responsables, para su corrección. La propuesta se envía por correo electrónico institucional a la jefatura responsable de corregir dicho documento, el cual ha de ser leído, corregido y nuevamente enviado por correo electrónico al responsable para realizar los ajustes correspondientes. Con ello, las correcciones de las propuestas se individualizan en los investigadores que producen estos primeros esbozos, lo que permite definir al responsable de corregir los errores cometidos o los análisis que hay que enmarcar. Este proceso de evaluación interna resulta clave en la elaboración de los boletines, ya que estas recomendaciones deben ser -necesariamente- asumidas como "ajustes necesarios" por parte de los productores. De esta forma, el responsable del análisis propuesto debe seguir lo estipulado en las observaciones realizadas, de lo contrario se arriesga caer en un conjunto de refutaciones y enmarcamientos jerárquicos a su análisis y su conducta como investigador de esta organización.

Cuando yo escribí el primer boletín y fue enviado a la jefa, la jefa lo destruyó en el sentido de que nadie iba a entenderlo, uno está acostumbrado 
a palabras técnicas, y para uno no es de difícil lectura, pero ella me decía: "Esto no lo puede leer una persona en su casa, no va a entender ni una palabra, hay que decirlo en simple", y ahí tuve que hacer toda la redacción de nuevo, los resultados eran los mismos pero tenía que hablar en otras palabras. Tuve que traducirlo, eso me costó harto, porque yo lo entiendo, porque estoy tan acostumbrada a estas palabras que no me doy cuenta. (Fragmento de una entrevista a la socióloga del Observatorio SENDA.)

En este contexto, los procesos de traducción (Callon, 1995) a los que está asociado la elaboración de un boletín comienzan a multiplicarse. Primero, a partir de los análisis individuales que cada investigador realiza a partir de su trabajo en las bases de datos, luego, a partir de las discusiones y debates entre los integrantes del equipo del Observatorio, y finalmente, en los procesos de corrección y ajustes por realizar. La producción de boletines está marcada por una estructuración disciplinar que se aplica por los actores con mayor rango y poder jerárquico en la institución, siguiendo dos focos de interés, por un lado desde la salud pública (una aproximación epidemiológica) y, por otro lado, desde la estadística econométrica. Uno de los economistas comenta esta tensión:

Yo trabajo con bases de datos, lo que yo puedo hacer es encontrar asociaciones, entonces yo observo que hay una relación entre la prevalencia de consumo de tabaco y consumo simultáneo con alcohol. Yo aquí no estoy diciendo que el consumo de alcohol está asociado con el consumo de tabaco; sino que lo que yo observo es que hay una asociación entre estos dos y que entonces hay ciertos factores comunes a la hora de comparar estos dos, a través de la hipótesis que presento en un comienzo, y lo que yo extraigo entonces de los datos son asociaciones. Bajo esa lógica, yo no puedo hacer relaciones causales. (Fragmento de una entrevista al economista del Observatorio SENDA.)

Estas tensiones disciplinares entre enfoques de la salud pública (análisis epidemiológicos) y la estadística econométrica (análisis probabilísticos) se presentan constantemente a la hora de coordinar el trabajo cotidiano del equipo del Observatorio. En algunos casos, la elaboración de los boletines queda más vinculada a un enfoque que otro, dependiendo de la profesión del investigador y su capacidad de argumentar sus análisis frente a los actores que juegan un rol de punto de paso obligado. Esto se ve expresado en la diversidad de temas que abarcan estos boletines, como lo muestra la tabla 1. 
Tabla 1. Temas de los boletines

\begin{tabular}{|c|c|}
\hline Nombre & Resumen \\
\hline $\begin{array}{l}\text { Boletín 1: El mercado de la } \\
\text { marihuana }\end{array}$ & $\begin{array}{l}\text { El presente boletín aborda estas dificultades para el mercado de la } \\
\text { marihuana, teniendo como objetivos obtener una medida que sirva } \\
\text { como parámetro de referencia para las cantidades de esta droga. Para } \\
\text { ello se utilizan los datos sobre consumo mensual de marihuana } \\
\text { reportados por los Estudios Nacionales de Drogas en Población } \\
\text { General (ENPG) para los años 2004, 2006, } 2008 \text { y 2010, y los datos de } \\
\text { decomisos de marihuana reportados en los Informes Nacionales de } \\
\text { Procedimientos por Infracción a la Ley de Drogas N } 20.000 \text { de la } \\
\text { División de Seguridad Pública (DSP). }\end{array}$ \\
\hline $\begin{array}{l}\text { Boletín 2: Octavo estudio } \\
\text { nacional en población escolar } \\
\text { de Chile. Resultados escala } \\
\text { Cannabis Abuse Screening Test } \\
\text { (CAST) }\end{array}$ & $\begin{array}{l}\text { El presente boletín analiza los resultados del CAST con la escala de } \\
\text { respuestas Likert de } 5 \text { puntos en cada una de las preguntas (rango } 6 \text { y } \\
\text { 30). El objetivo es dar a conocer los resultados del análisis de la } \\
\text { composición de la escala CAST empleando como fuente de información } \\
\text { de la base de datos correspondiente al Octavo Estudio Nacional en } \\
\text { Población Escolar 2009. }\end{array}$ \\
\hline $\begin{array}{l}\text { Boletín 3: Análisis de } \\
\text { resultados. Alcohol Use } \\
\text { Disorders Identification Test } \\
\text { (AUDIT) }\end{array}$ & $\begin{array}{l}\text { En el siguiente boletín se presentarán los resultados de la escala AUDIT } \\
\text { que se aplicó en el Noveno Estudio Nacional de Drogas en Población } \\
\text { General de Chile, comparando los puntos de corte de la versión } \\
\text { original del instrumento elaborado por la oMs con los obtenidos en la } \\
\text { validación chilena (ENPG, 2010). }\end{array}$ \\
\hline $\begin{array}{l}\text { Boletín 4: Caracterización de } \\
\text { los niveles de consumo de } \\
\text { alcohol en Chile }\end{array}$ & $\begin{array}{l}\text { En este boletín se explora la influencia de variables como sexo, } \\
\text { escolaridad, edad e ingreso en la probabilidad de presentar un } \\
\text { determinado nivel de consumo. Este análisis se llevó a cabo utilizando } \\
\text { la base de datos del Noveno Estudio Nacional de Drogas en Población } \\
\text { General del año 2010, mediante un modelo de regresión multinomial. }\end{array}$ \\
\hline $\begin{array}{l}\text { Boletín 5: Victimización y } \\
\text { alcohol. Asociación entre } \\
\text { frecuencia mensual y consumo } \\
\text { de alcohol con reporte de } \\
\text { eventos violentos }\end{array}$ & $\begin{array}{l}\text { En este boletín se desarrollan las asociaciones entre el consumo } \\
\text { intenso, la frecuencia mensual de consumo de alcohol y la } \\
\text { probabilidad de ser víctima de algún episodio de violencia relacionado } \\
\text { con el consumo de alcohol u otras drogas. El análisis consideró a los } \\
\text { participantes de la Octava y Novena Encuesta Nacional de Drogas en } \\
\text { población General. Los participantes incluidos en este boletín tienen } \\
\text { entre } 12 \text { y } 64 \text { años y se incluyó a todos aquellos que contestaron las } \\
\text { preguntas de interés (cuestionario AUDIT). }\end{array}$ \\
\hline $\begin{array}{l}\text { Boletín 6: Factores de riesgo y } \\
\text { consumo de marihuana en la } \\
\text { población escolar }\end{array}$ & $\begin{array}{l}\text { En este boletín se estimó la probabilidad de presentar consumo de } \\
\text { marihuana durante los últimos treinta días utilizando el Octavo Estudio } \\
\text { Nacional de Drogas en Población Escolar de Chile del año } 2009 .\end{array}$ \\
\hline $\begin{array}{l}\text { Boletín 7: Edad de inicio en el } \\
\text { consumo de alcohol y tabaco: } \\
\text { Cohortes 1934-1994 }\end{array}$ & $\begin{array}{l}\text { El objetivo de este boletín fue estimar la edad de inicio en el consumo } \\
\text { de alcohol y tabaco según año de nacimiento, para lo cual se } \\
\text { utilizaron los nueve estudios nacionales de drogas en población } \\
\text { general de Chile realizados entre } 1994 \text { y } 2010 \text {. }\end{array}$ \\
\hline
\end{tabular}




\begin{tabular}{|c|c|}
\hline Nombre & Resumen \\
\hline $\begin{array}{l}\text { Boletín 8: Precio y gasto de } \\
\text { droga ilícita en Chile }\end{array}$ & $\begin{array}{l}\text { El objetivo del presente boletín es entregar información relativa al } \\
\text { precio que se paga por las principales drogas ilícitas consumidas en } \\
\text { Chile y al gasto mensual que se realiza en este ítem, según nivel } \\
\text { socioeconómico. Se utilizó información obtenida a partir de los } \\
\text { Estudios Nacionales de Drogas en Población General entre los años } \\
2004 \text { y 2010, en población prevalente, año y mes de consumo de } \\
\text { sustancia, según la variable analizada. }\end{array}$ \\
\hline $\begin{array}{l}\text { Boletín 9: Caracterización de la } \\
\text { población femenina atendida } \\
\text { en el programa de tratamiento } \\
\text { especifico de mujeres }\end{array}$ & $\begin{array}{l}\text { El presente boletín tiene como objetivo describir el perfil de las } \\
\text { usuarias del tratamiento específico de mujeres perteneciente al } \\
\text { Servicio Nacional para la Prevención y Rehabilitación del Consumo de } \\
\text { Drogas y Alcohol (SENDA), que se atienden en centros públicos y } \\
\text { privados del país. Se utilizarán datos extraídos de los registros del } \\
\text { sistema informático, Sistema de Información y Gestión de Tratamiento } \\
\text { (SISTRAT) del año } 2011 \text {. }\end{array}$ \\
\hline $\begin{array}{l}\text { Boletín 10: Estudio piloto en } \\
\text { población escolar: ¿la } \\
\text { estructura del cuestionario } \\
\text { importa? }\end{array}$ & $\begin{array}{l}\text { El presente boletín tiene por objetivo analizar cómo la estructura de } \\
\text { un cuestionario aplicado en población escolar -para medir consumo } \\
\text { de drogas- puede afectar la cantidad de respuestas y la concordancia } \\
\text { entre estas, a partir de un estudio piloto realizado de manera previa al } \\
\text { desarrollo del Noveno Estudio Nacional de Drogas en Población } \\
\text { Escolar de Chile (SENDA, 2011), con el objetivo de generar evidencia } \\
\text { que ayudara a decidir qué formato funcionaba de mejor manera entre } \\
\text { los alumnos. }\end{array}$ \\
\hline $\begin{array}{l}\text { Boletín 11: Orquestas juveniles } \\
\text { como factor protector }\end{array}$ & $\begin{array}{l}\text { El presente boletín tiene como objetivo conocer si la participación en } \\
\text { las orquestas juveniles constituye un factor protector del consumo del } \\
\text { alcohol y otras drogas. Para ello, se utilizan datos proporcionados por } \\
\text { un instrumento de autodiagnóstico de factores de riesgo y protectores } \\
\text { aplicado a una muestra de participantes de las orquestas juveniles y } \\
\text { datos del Octavo Estudio Nacional de Drogas en Población Escolar de } \\
\text { Chile. }\end{array}$ \\
\hline $\begin{array}{l}\text { Boletín 12: Marihuana como } \\
\text { puerta de ingreso a otras } \\
\text { drogas }\end{array}$ & $\begin{array}{l}\text { El presente boletín busca evaluar la hipótesis de la marihuana como } \\
\text { puerta de entrada al consumo de otras drogas con mayor efecto } \\
\text { adictivo (cocaína o pasta base) en estudiantes de } 13 \text { a } 18 \text { años. Para } \\
\text { ello, se utilizaron datos del Octavo Estudio Nacional de Drogas en } \\
\text { Población Escolar de Chile, realizado en el año } 2009 \text {. }\end{array}$ \\
\hline
\end{tabular}

\section{Una publicación orientada por diferentes retóricas científicas}

El boletín también es un objeto que está atravesado, producido e integrado por discursos que, desde diferentes instancias locales y globales, se buscan profundizar en los diferentes Estados. Uno de ellos ha sido el discurso de las políticas públicas basadas en evidencias. 
Lo que se quería hacer era generar un órgano competente para que pueda generar conocimiento bajo la lógica de explotar las bases de datos y otro las evaluaciones de impacto, que son temas muy de moda cuando asume este nuevo gobierno. Este nuevo gobierno crítica a las administraciones anteriores ya que anteriormente no se evaluaba nada, entonces nació el concepto de que todo programa que se haga tiene que estar basado en evidencias, con una evaluación incorporada. Entonces, dentro de estos objetivos, que eran generar conocimiento, la jefa de División Programática nos comentaba que sería bueno que empezáramos a generar conocimiento científico a través de artículos. (Fragmento de una entrevista al economista del Observatorio SENDA.)

\section{Una publicación elaborada por datos cuantitativos recolectados anteriormente}

Los boletines son publicaciones que poseen análisis de datos estadísticos, datos e información que ya han sido elaborados metodológicamente en años anteriores, proceso que forma parte de la implementación del Programa Bienal de Estudios de Población General y está enfocado a la extracción de datos de: 1) estudios nacionales (Informes correspondientes a estudios sobre consumo de drogas en población general y población escolar); 2) estudios en poblaciones específicas (investigaciones sobre consumo de drogas y factores asociados en determinados sectores de personas) y 3) otras estadísticas de consumo de drogas en la región (datos de interés respecto del fenómeno de las drogas, recopilados por SENDA y otras instituciones especializadas).

\section{Una publicación que refleja una práctica investigativa de los científicos sociales}

El boletín es el producto primordial de la coordinación entre los investigadores sociales del Observatorio, los cuales van poco a poco negociando y estableciendo alianzas internas que posibilitan la elaboración de este nuevo objeto (producto de su trabajo cotidiano). En este contexto, elaborar un boletín no solo es un logro individual y organizacional, es también un logro en los procesos de coordinación entre todos los actores humanos (investigadores, jefes de División, encargado de Comunicaciones, directora nacional, etc.) y no-humanos involucrados (computadores, archivos electrónicos, 
programas computacionales, datos estadísticos, manuales, otros estudios, oficios, etc.). El hecho de que un boletín sea aprobado y luego publicado determina el logro de la coherencia de estos procesos de producción de conocimiento científico-social, lo que permite definir si es que el proceso continúa (o no) funcionando con éxito.

Uno de los economistas del equipo señala en una de las entrevistas:

[...] lo que se quería hacer era generar un órgano competente para que pueda generar conocimiento bajo la lógica de que uno explota las bases de datos y otro se mete con las evaluaciones de impacto, que son temas muy de moda cuando asume este nuevo gobierno [...] La crítica que se hacía a la administraciones anteriores era que no evaluaban nada, entonces nació el concepto de que todo programa que se haga tiene que estar basado en evidencias, con una evaluación incorporada. (Fragmento de una entrevista a economista del Observatorio SENDA.)

De esta manera, el equipo de profesionales del observatorio busca orientar su trabajo para construir estas publicaciones; aquí se debaten estudios en la materia, buscando establecer puntos de reflexión común entre los miembros del Observatorio. Se revisan constantemente las bases de datos electrónicas (Estudios Nacionales de Consumo de Drogas y Alcohol) y los resultados y análisis realizados en los informes de resumen que cada Estudio Nacional contemplaba.

\section{Una publicación que busca ser difundida a un público no experto en la materia}

Frente a las exigencias institucionales por publicar mensualmente boletines, se va consolidando una determinada uniformidad de los procesos de elaboración, donde conviven estas tensiones disciplinares que estructuran los procesos de elaboración del boletín. Una vez que un boletín ha logrado ser corregido por parte de estos actores y nuevamente sometido a procesos de revisión (no existe un criterio preestablecido para las revisiones y correcciones, esto se define de manera contingente), logra ser aprobado por parte de la autoridad correspondiente, en este caso, la directora nacional determinará en última instancia si es que la propuesta presentada (luego de haber sido corregida y modificada) logra ser considerada como un boletín. Un nuevo proceso emerge en la elaboración de este artefacto, el cual no depende necesariamente de los profesionales del Observatorio, ni de la jefa de División 
o incluso de la directora nacional. El boletín debe "lucir atractivo" en su diseño, es decir, su tipografía, su portada, sus colores deben ser representativos de la institución, sus gráficos deben estar estandarizados. La elaboración de este boletín, como un objeto que actualiza y resignifica una serie de datos estadísticos de mediciones estatales de drogas, involucra una intervención gráfica y estética fundamental para plasmar el mensaje por entregar institucionalmente. Como un dispositivo completamente nuevo, original e innovador.

Una vez finalizada su elaboración conceptual y metodológica, el boletín se le envía por correo electrónico al encargado de Comunicaciones del SENDA, sus conocimientos le servirán al boletín para no parecer un informe más. Este actor que se suma al proceso de elaboración del boletín modifica este artefacto a través de programas computacionales de diseño gráfico como InDesign o Photoshop, logrando concretar un largo proceso de construcción de un boletín. Pero esta nueva edición no es tan clara, ya que se menciona que incluso este actor puede llegar a modificar la redacción de textos que no sean "entendibles" para el público general. Luego de esta nueva intervención, el proceso de elaboración interna del boletín finaliza; la próxima instancia del boletín será su publicación en la página web del SENDA (en formato PDF: Portable Document Format), y el envío a través de lista de correos masivos a los correos que estén suscritos al sistema de Newsletter del SENDA. Estas serán sus primeras vías de salida al mundo exterior.

Se supone que la idea inicial de los boletines sea para que gente común y corriente pueda leerlos y entenderlos. De ahí que muchas veces escribimos de una manera y tenemos que bajarlo, bajarlo y dejarlo muy básico. Ahora, si eventualmente yo voy a hablar de un cambio en la razón de prevalencia, ya por el solo hecho de que se está hablando de esta herramienta tienes que manejar algo del tema [...]. Uno trata de buscar la forma más fácil para presentarlo, pero si yo lo planteo como puntos de la razón de prevalencia no se entiende. Uno tiene que tratar de dejarlo más fácil. (Fragmento de una entrevista a antropólogo del Observatorio SENDA.)

\section{Una publicación que busca validación en una comunidad científica}

El boletín es una publicación difundida en espacios disciplinares y estatales, específicamente con determinados grupos de interés por el fenómeno de la drogadicción. Es lo que la directora del Servicio ha llamado Comité Científico del Observatorio, al cual lo integran desde expertos académicos 
de diferentes universidades del país hasta representantes de las policías, del Poder Legislativo, de fundaciones y organizaciones no gubernamentales, entre otros. ${ }^{[12]}$ Aquí el boletín deja de ser un conjunto de conocimientos en elaboración y es presentado por sus productores, los científicos del Observatorio, como un documento oficial, un objeto del conocimiento especializado y objetivo, que busca ser comentado, criticado, pero sobre todo, validado. Se busca un muy específico posicionamiento de los conocimientos producidos, que se arriesgan -en cierto sentido-a ser falseados, pero también legitimados y declarados como regímenes de verdad. Esta ciencia elaborada por los investigadores del Observatorio está en movimiento, en búsqueda de legitimidad en un campo científico heterogéneo; pero también en espacios políticos, que permiten posicionar el conocimiento producido.

\section{Una publicación transnacional}

El boletín, además, desarrolla una capacidad de vinculación con contextos globales y transnacionales. Una de las dimensiones emergentes que aparecieron en todos los entrevistados fueron las conexiones internacionales. El Observatorio es parte de una red de observatorios en América Latina, el Caribe, Norteamérica y la Unión Europea. Gran parte de las instancias para poder discutir los resultados de los boletines que cada observatorio está realizando se dan en este tipo de instancias, a través de seminarios, conferencias y capacitaciones que son organizados por Naciones Unidas (ONU), la Organización de Estados Americanos (OEA) o la Unión Europea (UE).

Los investigadores del Observatorio destacan la importancia que tiene la participación activa en estas instancias transnacionales, las cuales tienen diferentes suborganizaciones especializadas en el estudio de la drogadicción como problema social en América Latina, tales como la Comisión Interamericana para el Control del Abuso de Droga (CICAD), el Programa de Cooperación entre América Latina, el Caribe y la Unión Europea en Políticas sobre Drogas (copolat), o la Oficina de las Naciones Unidas contra la Droga y el Delito (ONUDC), entre otras.

[12] Diversas fueron las reuniones que sostuvo este comité científico asesor del SENDA, en el cual participaban activamente el director de la Escuela de Salud Pública de la Universidad de Chile, el director del Centro de Microdatos de la Universidad de Chile, el director de la Fundación Paz Ciudadana, el director de la Fundación Paréntesis, el director del Centro de Información Toxicológica de la Universidad Católica (CITUC), representantes de Carabineros de Chile y la Policía de Investigaciones, entre otros. 
Todas ellas son vistas - por parte de los investigadores que producen el boletín- como un espacio global que les permite reactivar, profundizar, compartir y discutir los resultados de los boletines. Para ellos, estas son las audiencias efectivas, debido a que se maneja un lenguaje técnico necesario a la hora de explicar y entender el conocimiento ahí producido. Este posicionamiento estuvo en la base de toda una articulación diplomática de ciertos actores chilenos que han tomado protagonismos en estas organizaciones, tales como Francisco Cumsille y Juan Carlos Araneda, autoridades de la CICAD y ONUDC, respectivamente. Esto sumado a la participación de académicos como el jefe del Observatorio o la jefa de la División de Tratamiento del SENDA, que han tenido muy activa participación en estas instancias, algunos incluso antes que entraran a la propia SENDA.

Chile es parte del Observatorio Sub Regional de Drogas, que es el conjunto de Observatorios que integran la región, por países. Su finalidad es el monitoreo del consumo de drogas, en ese marco subregional se discute la batería de instrumentos, por ejemplo ahí está muy metido el tema del CAST. Ese subregional está a cargo de la CICAD, que es la Comisión Internacional para el Control del Abuso de Drogas, que depende de la oza. Este es el principal contexto que tienen los observatorios para poder discutir en torno a temas más específicos y son instancias donde surgen discusiones con respecto a las políticas públicas y a planes de control, prevención y tratamiento. Porque en el fondo de todo esto hay muchos estudios de carácter comparativo usando por ejemplo datos de población escolar. Entonces tenemos harto feedback con los otros observatorios. (Fragmento de una entrevista a antropólogo del Observatorio SENDA.)

Es clave entender cómo se posiciona aquí el boletín. En instancias internacionales como estas el conocimiento producido ya ha sido depurado por diversos actores, comunidades o instituciones y no se cuestiona su validez o relevancia. Los criterios de publicación, las normas editoriales, las formas de presentación de resultados, el lenguaje utilizado y una serie de elementos se presentan como verdad objetiva y legitimada a nivel local.

En el seminario al que fuimos había países que no hacen investigaciones tan periódicas como nosotros en Chile, entonces se le daba énfasis a eso, que se mostraban gráficos y Brasil tenía hasta un ańo solamente evidencia, que no hay información actual entonces sobre cómo comparar, cómo saber, es importante; y el profesor decía ahí que mantengan la información actualizada, que en el fondo convenzan a sus autoridades de que es necesario, se 
daba harto énfasis en eso, entonces claro, al mirar pal lado tu decías mira, somos el único país que no tiene la información actualizada, o sea, tenemos que ponernos al día, yo creo que eso tiene que servir. (Fragmento de una entrevista a psicólogo del Observatorio SENDA.)

Con ello, creemos que estas características permiten conceptualizar al boletín como un Boundary Object (Star y Greiseimer, 1986), es decir, como el resultado de la cooperación entre actores (humanos y no humanos) que buscan delimitar un fenómeno de estudio, que, a su vez, represente la diversidad disciplinar y puntos de vista que lo han producido. Este boletín es un objeto que tiene la capacidad de conectar con otros actores, contextos y campos. En términos generales, el boletín es un objeto que puede ser concreto y abstracto a la vez, puede además incorporar en sus análisis grandes cantidades de información y enfoques, así como puede ser un mecanismo para posicionar nuevas temáticas en la conceptualización y estudio de la drogadicción desde el Estado.

El conjunto de posibilidades de producción y difusión que tiene el boletín, entendido como un Boundary Object, le permiten ensamblarse y generan agenciamientos sociotécnicos (Latour, 2005) en al menos tres instancias que se pueden diferenciar en tres formas de objetos: 1) Objeto en Elaboración: caracterizado por la individualización de la producción, horizontalización inicial de las relaciones de producción, deliberación de los procesos de producción inicial, flexibilidad en la producción, jerarquización epistémica en los procesos de revisión y una estandarización de los métodos, técnicas, datos y enfoques utilizados; 2) Objeto Disciplinar: es una publicación oficial de un organismo estatal, se busca generar una alta difusión a grupos de interés específicos y se presenta una fuerte influencia en el despliegue de este objeto por parte de una comunidad científica especializada, la cual sirve como fuente de legitimación del conocimiento que contiene y moviliza el boletín; 3) Objeto Global: el boletín también se ensambla como un objeto global, el cual es un conocimiento científico objetivo y oficial del Estado chileno en materia de drogadicción, cuenta con instancias específicas donde es difundido y comunicado, y ha sido producido por pautas sistemáticas y rigurosas en la aplicación de las técnicas y uso de información.

En estos tres ensamblajes el boletín es primero elaborado, luego legitimado y por último difundido como un objeto eficiente y objetivo. Esto es lo que constituye a este objeto como un mecanismo performativo, el cual es por un lado resultado de un conjunto de asociaciones entre actores (humanos y no humanos), pero además tiene la capacidad de influir en la realidad, de describirla y estructurarla. Estas son sus principales caracterís- 
ticas a la hora de ser analizado en su dimensión relacional, que lo constituyen como el principal resultado del trabajo coordinado de un equipo multidisciplinar en el interior Estado chileno.

\section{CONCLUSIONES}

En este artículo hemos intentado extender la noción de producción de conocimientos científicos de problemas sociales en la esfera pública en Chile. Este dispositivo de poder gubernamental (Ramos, 2012 y 2016) es lo suficientemente diferenciado en términos teóricos (Foucault, 2005 y 2006) y metodológicos (Hammersley y Atkinson, 2001). Los procesos de producción de conocimiento del fenómeno de la drogadicción, entendido como un problema social, han sido estructurados por el Estado a través de diferentes mecanismos y dispositivos epistémicos (Foucault, 2005 y 2006) en una estrecha alianza con las ciencias sociales, con sus conocimientos y métodos de investigación de cohorte positivista, lo que hemos denominado como un nuevo poder gubernamental del Estado. Estos mecanismos tienen una capacidad performativa (Ramos, 2016) sobre la realidad, es decir, describen y construyen la realidad a partir de este tipo de fenómenos.

Con este análisis, hemos podido descifrar el rol preponderante del Estado y su vinculación con las ciencias sociales, vinculadas a la construcción de problemáticas sociales, cuestión que ha ocurrido en Chile hace aproximadamente treinta años. Así, diversos organismos públicos, organizaciones no gubernamentales y el mundo académico de las universidades contribuyen día a día a la elaboración y resignificación de datos, información y conocimiento en el SENDA, estudiando las prácticas científicas enfocadas a elaborar publicaciones, que como hemos podido evidenciar convergen con la emergencia del boletín como un Boundary Object, el cual posee una diferenciación funcional según los espacios y actores con los que interactúa. Este objeto puede ser flexible como a la vez robusto, soportar estructuras jerarquizadas, orientarse epistemológicamente y estandarizar análisis, métodos y datos, movilizar conocimientos y validarse disciplinarmente. Así, el boletín orienta la producción de conocimientos científicos sociales que comienzan a articular un régimen de verdad sobre el consumo de droga en la esfera pública en Chile.

En esta línea, el boletín es también un dispositivo performativo del poder gubernamental que, a través de diversas estrategias científicas, busca delimitar, posicionar y legitimar formas gubernamentales de conceptualizar el fenómeno de la drogadicción en Chile. En este caso, el boletín como 
objeto vuelve totalmente objetiva la compleja, multidimensional y heterogénea realidad de la drogadicción, que ahora se aloja como hecho científico en el Estado. Se constituye, así, como un artefacto eficiente de la gubernamentalidad (Ramos, 2012 y 2016).

La preponderancia de las publicaciones científicas en la esfera pública, como el boletín, así como también de las organizaciones que lo producen (observatorios, centros de estudios, laboratorios de datos, departamentos de evaluación, etc.) son un modelo que ha tenido un considerable auge en el interior del Estado chileno desde comienzos de siglo xxi y se han convertido, en muchos casos, en las garantías de la gestión pública eficiente del Estado.

Creemos que este tipo de análisis presenta una oportunidad para el estudio empírico y el ejercicio autorreflexivo que las ciencias sociales no deben abandonar, lo cual puede contribuir a futuro con nuevas pesquisas de las formas de construcción de órdenes sociales emergentes y sus mecanismos, objetos y conocimientos involucrados en la estandarización de personas y realidades. Nuestra inmersión en este mundo desconocido e invisibilizado en los informes, documentos oficiales y evidencias nos llevó a describir nuestras observaciones de un objeto en particular, el cual resultó ser donde comenzaban muchas de las acciones y actividades cotidianas de los investigadores del Observatorio, pero a su vez, donde comenzaban a definirse inicialmente los parámetros epistémicos de la drogadicción como un problema social en la esfera pública en Chile.

\section{REFERENCIAS BIBLIOGRÁFICAS}

Arriagada, I. y M. Hopenhayn (2000), Producción, tráfico y consumo de drogas en América Latina, Santiago de Chile, CEPAL.

Becker, H (2010), Trucos del oficio. Cómo conducir su investigación en ciencias sociales, Buenos Aires, Siglo Veintiuno.

Berger, P. y T. Luckmann (1967), La construcción social de la realidad, Buenos Aires, Amorrortu.

Bourdieu, P. (2012), Sur L'Etat. Cours au Collège de France, 1980-1992, París, Editions Raisons d'Agir / Editions du Seuil.

Callon, M. (1995), "Algunos elementos para una sociología de la traducción: la domesticación de las vieiras y los pescadores de la bahía de St. Brieuc", en Iranzo, J. M. et al. (coords.), Sociología de la ciencia y la tecnología, Madrid, C.s.I.C., pp. 91-104. 
Carroll, P. (2006), Science, Culture, and Modern State Formation, Berkeley, University of California Press.

conace (1994), Estudio Nacional de Consumo de Drogas, Consejo Nacional para el Control de Estupefacientes (Secretaría Ejecutiva), Ministerio del Interior, Gobierno de Chile.

— (1996), Segundo Estudio Nacional de Consumo de Drogas, Consejo Nacional para el Control de Estupefacientes (Secretaría Ejecutiva), Ministerio del Interior, Gobierno de Chile.

- (1998), Tercer Estudio Nacional de Consumo de Drogas, Consejo Nacional para el Control de Estupefacientes (Secretaría Ejecutiva), Ministerio del Interior, Gobierno de Chile.

- (2000), Cuarto Estudio Nacional de Consumo de Drogas, Consejo Nacional para el Control de Estupefacientes (Secretaría Ejecutiva), Ministerio del Interior, Gobierno de Chile.

- (2003), Quinto Estudio Nacional de Consumo de Drogas en Población General, Consejo Nacional para el Control de Estupefacientes (Secretaría Ejecutiva), Ministerio del Interior, Gobierno de Chile.

- (2004), Sexto Estudio Nacional de Consumo de Drogas en Población General, Consejo Nacional para el Control de Estupefacientes (Equipo Responsable: Área de Evaluación y Estudios), Ministerio del Interior, Gobierno de Chile.

- (2006), Séptimo Estudio Nacional de Consumo de Drogas en Población General, Consejo Nacional para el Control de Estupefacientes (Equipo Responsable: Área de Evaluación y Estudios), Ministerio del Interior, Gobierno de Chile.

- (2008), Octavo Estudio Nacional de Consumo de Drogas en Población General. Consejo Nacional para el Control de Estupefacientes (Equipo Responsable: Área de Evaluación y Estudios), Ministerio del Interior, Gobierno de Chile.

- (2011), Estrategia Nacional de Drogas y Alcohol, 2011-2014, Ministerio del Interior y Seguridad Pública, Gobierno de Chile.

Congreso Nacional de Chile (1969), Ley No 171.555, Modifica Código Penal en lo relativo a delitos contra la Salud Pública y Códigos de Procedimientos penal y sanitario, Santiago de Chile, Biblioteca del Congreso Nacional.

— (1973), Ley No 17.934, Reprime el tráfico de Estupefacientes, Santiago de Chile, Biblioteca del Congreso Nacional.

(1985), Ley No 18.403. Sanciona el tráfico ilícito de drogas y estupefacientes y deroga la Ley $N^{o}$ 17.934, Santiago de Chile, Biblioteca del Congreso Nacional. 
(1995), Ley No 19.366. Sanciona el tráfico ilícito de estupefacientes y sustancias sicotrópicas, dicta y modifica diversas disposiciones legales y deroga Ley $N^{o}$ 18.403, Santiago de Chile, Biblioteca del Congreso Nacional.

- (1995), Ley No 19.419. Regula actividades que indica relacionadas con el tabaco, Santiago de Chile, Biblioteca del Congreso Nacional.

- (2004), Ley No 19.925. Ley sobre expendio y consumo de bebidas alcohólicas, Santiago de Chile, Biblioteca del Congreso Nacional.

— (2005), Ley No 20.000. Sustituye la Ley No 19366, que sanciona el tráfico ilícito de estupefacientes y sustancias sicotrópicas, Santiago de Chile, Biblioteca del Congreso Nacional.

- (2011), Ley No 20.502. Crea el Ministerio del Interior y Seguridad Pública y el Servicio Nacional para la Prevención y Rehabilitación del Consumo de Drogas y Alcohol, y modifica diversos cuerpos legales, Santiago de Chile, Biblioteca del Congreso Nacional.

Denzin, N. e Y. Lincoln (eds.) (2008), The landscape of Qualitative Research. Theories and Issues, Londres, Sage.

Desrosières, A. (2004), La política de los grandes números, Barcelona, Editorial Medusina.

Fernández Labbé, M. (2013), "Boticas y toxicómanos: origen y reglamentación del control de drogas en Chile, 1900-1940”, Atenea, No 508, pp. 73-89.

Florenzano Urzua, R. (1989), "Alcoholismo y abuso de otras drogas: Programas de prevencion en Santiago, Chile", Boletín de la Oficina Sanitaria Panamericana, vol. 107, No 6.

Foucault, M. (2000), Vigilary Castigar. Nacimiento de la prisión, Buenos Aires, Siglo XXI.

- (2002), Defender la sociedad. Curso en el Collège de France (1975-1976), México, Fondo de Cultura Económica.

— (2005), El Poder psiquiátrico, Buenos Aires, Fondo de Cultura Económica. (2006), Seguridad, territorio y población, Buenos Aires, Fondo de Cultura Económica.

- (2007), Nacimiento de la biopolítica. Curso en el Collège de France (19781979), Ciudad de México, Fondo de Cultura Económica.

- (2009), El gobierno de sí y de los otros. Curso en el Collège de France (19821983), México, Fondo de Cultura Económica.

Garmendia, M. L., M. E. Alvarado, M. Montenegro y P. Pino (2008), "Importancia del apoyo social en la permanencia de la abstinencia del consumo de drogas", Revista médica de Chile, vol. 136, No 2, pp. 169-178.

Geertz, C. (1992), Descripción densa: hacia una teoría interpretativa de la cultura. La interpretación de las culturas, Barcelona, Gedisa. 
Goffman, E. (1989), "On fieldwork", Journal of Contemporary Ethnography, vol. 18, No 2, pp. 123-132.

Guba, E. G. e Y. S. Lincoln (1998), "Competing paradigms in social research", The landscape of qualitative research, No 7, pp. 195-220.

Guba, E. e Y. Lincoln (2002), "Paradigmas en competencia en la investigación cualitativa”, en Denman, C. y J. A. Haro (comps.), Por los rincones. Antología de métodos cualitativos en la investigación social, Sonora, El Colegio de Sonora, pp. 113-145.

Hammersley, M. y P. Atkinson (2001), Etnografía: métodos de investigación, Barcelona, Paidós.

Hopenhayn, M. (1997), La grieta de las drogas: desintegración social y politicas públicas en América Latina, Santiago de Chile, CEPAL.

- I. D. Rementería y G. Sunkel (1999), Criterios básicos para una política de prevención y control de drogas en Chile, Santiago de Chile, CepaL.

Knorr Cetina, K (2005), La fabricación del conocimiento. Un ensayo sobre el carácter constructivista y contextual de la ciencia, Buenos Aires, Editorial de la Universidad Nacional de Quilmes.

Kreimer, P. y J. P. Zabala (2007), "Producción de conocimientos científicos y problemas sociales en países en desarrollo", Nómadas, N. ${ }^{\circ} 27$, pp. $110-122$.

Latour, B. (2005), Reassembling the Social: An Introduction to Actor-Network Theory, Oxford, Nueva York, Oxford University Press.

— y S. Woolgar (1979), Laboratory Life: The Social Construction of Scientific Facts, Londres y Beverly Hills, Sage.

Law, J. (2004), After Method. Mess in Social Science Research, Londres y Nueva York, Taylor \& Francis Group.

Lynch, M. (1985), Art and Artifact in Laboratory Science, Londres, Routledge.

Marrero, I. (2013), "Por una Teoría del Actor-Red menor: perspectivismo y monologia”, en Tirado, F. y D. López (comps.), Teoría del Actor-Red: Más allá de los Estudios de la Ciencia y la Tecnología, Barcelona, Amentia Editorial.

Ministerio de Hacienda de Chile (2009), Evaluación Programas de Prevención del Consumo de Drogas, Programas de Tratamiento y Rehabilitación y Programa Previene (Municipios), Dirección de Presupuestos (Dipres). Disponible en <http://www.dipres.cl/574/articles-49635_doc_pdf.pdf>. Ministerio de Salud Pública de Chile (1969), Decreto Con Fuerza De Ley 725. Código Sanitario, Santiago de Chile, Biblioteca del Congreso Nacional.

Porter, T. (1995), Trust in Numbers. The Pursuit of Objectivity in Science and Public Life, Princeton, Princeton University Press. 
(2003), "Genres and Objects of Social Inquiry, from the Enlightment to 1890”, en Porter, T. y D. Ross (eds.), The Modern Social Sciences, Cambridge, Cambridge University Press.

Ramos, C. (2005), "Cómo investigan los sociólogos chilenos en los albores del siglo xxi: Paradigmas y herramientas del oficio", Persona y Sociedad, vol. 19, No 3, pp. 85-119.

— (2012), El ensamblaje de ciencia social y sociedad. Conocimiento científico, gobierno de las conductas y producción de lo social, Santiago de Chile, Ediciones Universidad Alberto Hurtado.

— (2013), "Conocimiento científico-social, gubernamentalidad y gestión de empresas en Chile", en Ossandón, J. y E. Tironi (eds.), Adaptación. La empresa chilena después de Friedman, Santiago de Chile, Ediciones Universidad Diego Portales, pp. 167-198.

_ (2014), "Datos y relatos de la ciencia social como componentes de la producción de realidad social”, Convergencia: Revista de Ciencias Sociales, vol. 21, No 66, pp. 151-177.

(2015), Poverty as Epistemic Object of Government: State Cognitive Equipment and Social Sciences Operations, París, Social Science Information. - (2016), La producción de la pobreza como un objeto de gobierno, Santiago de Chile, Ediciones Universidad Alberto Hurtado.

Peruaga, A., A. Rincón y H. Selin (2002), "El consumo de sustancias adictivas en las Américas”, Adicciones, vol. 14, No 2, pp. 227-238.

Rebolledo, N. O. y M. C. S. Costa (2005), "Significados y contradicciones del fenómeno de las drogas: drogas lícitas e ilícitas en Chile", Revista LatinoAmericana de Enfermagem, No 13, pp. 903-911.

Sánchez, S. (2012), "La discusión de drogas en Chile", Revista Chilena de Salud Pública, vol. 16, No 3, pp. 210-211.

SEnda (2010), Noveno Estudio Nacional de Drogas en Población General de Chile, Observatorio Chileno de Drogas, Gobierno de Chile.

- (2012), Décimo Estudio Nacional de Drogas en Población General de Chile, Observatorio Chileno de Drogas, Gobierno de Chile.

- (2014), Décimo Primer Estudio Nacional de Drogas en Población General de Chile, Observatorio Chileno de Drogas, Gobierno de Chile.

- (2015a), Boletin 1: El mercado de la marihuana, Gobierno de Chile. (2015b), Boletin 2: Octavo estudio nacional en población escolar de Chile. Resultados escala Cannabis Abuse Screening Test (CAST), Gobierno de Chile. (2015c), Boletin 3: Análisis de resultados. Alcohol Use Disorders Identification Test (AUDIT), Gobierno de Chile.

- (2015d), Boletín 4: Caracterización de los niveles de consumo de alcohol en Chile, Gobierno de Chile. 
- (2015e), Boletín 5: Victimización y Alcohol. Asociación entre frecuencia mensual y consumo de alcohol con reporte de eventos violentos, Gobierno de Chile.

- (2015f), Boletín 6: Factores de riesgo y consumo de maribuana en la población escolar, Gobierno de Chile.

- (2015g), Boletin 7: Edad de inicio en el consumo de alcohol y tabaco: Cohortes 1934-1994, Gobierno de Chile.

- (2015h), Boletín 8: Precio y gasto de droga ilícita en Chile, Gobierno de Chile.

- (2015i), Boletín 9: Caracterización de la población femenina atendida en el programa de tratamiento especifico de mujeres, Gobierno de Chile.

- (2015j), Boletín 10: Estudio piloto en población escolar: ¿La estructura del cuestionario importa?, Gobierno de Chile.

- (2015k), Boletin 11: Orquestas juveniles como factor protector, Gobierno de Chile.

- (20151), Boletín 12: Marihuana como puerta de ingreso a otras drogas, Gobierno de Chile.

Star, L. S. y J. Griesemer (1989), "Institutional Ecology. Translations and Boundary objects: amateurs and professionals on Berkeley's Museum of Vertebrate Zoology”, Social Studies of Science, vol. 19, No 3, pp. 387-420.

Star, S. L. y K. Ruhleder (1996), "Steps toward an ecology of infrastructure: design and access for large information spaces", Information Systems Research, vol. 7, No 1, pp. 111-134.

Taylor, S. J. y R. Bogdan (2000), Introducción a los métodos cualitativos de investigación, Barcelona, Paidós.

Traweek, S. (2009), Beamtimes and lifetimes, Boston, Harvard University Press. Trompette, P. y D. Vinck (2009), "Regreso sobre la noción de objeto de frontera", Revue d'anthropologie des connaissances, vol. 3, No 1, pp. 4-26.

— (2010), "Volver Sobre la noción de Objeto-Frontera. Fecundidad de la noción en el análisis ecológico de los objetos innovadores", Revue d'anthropologie des connaissances, vol. 4, No 1, pp. 5-14.

Ureta, S. y N. Sanhueza (2018), "Emergencia de una disciplina: Los estudios CTs en el mundo y Latinoamérica”, en Espinosa-Rada, A., F. Ortiz y N. Sanhueza, Tecnopoliticas. Aproximaciones a los estudios de ciencia, tecnología y sociedad en Chile, Santiago de Chile, Ediciones Universidad Alberto Hurtado, pp. 19-66.

Valenzuela, E. y P. Larroulet (2010), “La relación droga y delito: Una estimación de la fracción atribuible", Estudios públicos, No 119, pp. 33-62.

Vinck, D. (2007), "Volver al Laboratorio como espacio de producción de conocimientos", Revue d'anthropologie des connaissances, vol. 1, No 2, pp. 161-167. 
Wagner, P. (2003), “The uses of social sciences”, en Porter, T. y D. Ross (eds.), The Modern Social Sciences, Cambridge, Cambridge University Pres, pp. 553-564.

Wolcot, H. (2006), "Etnografía sin remordimientos", Revista de Antropología Social, No 16, pp. 279-296.

Artículo recibido el 16 de marzo de 2018. Aprobado para su publicación el 7 de abril de 2020. 